\title{
Multivariable time-dependent analysis of the impact of azacitidine in patients with lower-risk myelodysplastic syndrome and unfavorable specific lower-risk score ${ }^{\text {is }}$
}

\author{
Jose Falantes $^{\mathrm{a}, *}$, Regina García Delgado ${ }^{\mathrm{b}}$, Cristina Calderón-Cabrera ${ }^{\mathrm{a}}$, \\ Francisco J. Márquez-Malaver ${ }^{\mathrm{a}}$, David Valcarcel ${ }^{\mathrm{c}}$, Dunia de Miguel ${ }^{\mathrm{d}}$, Alicia Bailén ${ }^{\mathrm{e}}$, \\ Joan Bargay $^{\mathrm{f}}$, Teresa Bernal ${ }^{\mathrm{g}}$, Jose R. González-Porras ${ }^{\mathrm{h}}$, Mar Tormo ${ }^{\mathrm{i}}$, Fernando Ramos ${ }^{\mathrm{j}}$, \\ Rafael Andreu $^{\mathrm{k}}$, Blanca Xicoy ${ }^{\mathrm{l}}$, Benet Nomdedeu ${ }^{\mathrm{m}}$, Salut Brunet ${ }^{\mathrm{n}}$, Joaquín Sánchez ${ }^{ }$, \\ Antonio Fernández Jurado ${ }^{\mathrm{p}}$, Santiago Bonanad ${ }^{\mathrm{q}}$, Jose Antonio Pérez-Simón ${ }^{\mathrm{a}}$, \\ Guillermo Sanz ${ }^{\mathrm{r}}$, for the Spanish Group of Myelodysplastic Syndromes (GESMD)
}

a Hospital Universitario Virgen del Rocío, Sevilla. Instituto de Biomedicina de Sevilla (IBIS)/CSIC/Universidad de Sevilla, Spain

${ }^{\mathrm{b}}$ Hospital Universitario Virgen de la Victoria, Málaga, Spain

' Hospital Universitario Vall d' Hebron, Barcelona, Spain

${ }^{\mathrm{d}}$ Hospital Universitario de Guadalajara, Guadalajara, Spain

e Hospital Carlos Haya, Málaga, Spain

${ }^{\mathrm{f}}$ Hospital Son Llatzer, Palma de Mallorca, Spain

${ }^{g}$ Hospital Universitario Central de Asturias, Spain

${ }^{\text {h }}$ Hospital Clínico Universitario de Salamanca, Salamanca, Spain

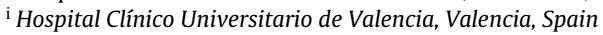

${ }^{\mathrm{j}}$ Hospital General de León, León, Spain

${ }^{\mathrm{k}}$ Hospital Doctor Peset, Valencia, Spain

${ }^{1}$ Hospital Germans Trias i Pujol, Badalona, Spain

${ }^{\mathrm{m}}$ Hospital Clinic, Barcelona, Spain

${ }^{\mathrm{n}}$ Hospital Santa Creu i Sant Pau, Barcelona, Spain

${ }^{\circ}$ Hospital Reina Sofía, Córdoba, Spain

Hospital Juan Ramón Jiménez, Huelva, Spain

q Hospital Universitario de la Ribera, Valencia, Spain

${ }^{\mathrm{r}}$ Hospital Universitario y Politécnico La Fe, Valencia, Spain ${ }^{2}$

\section{A R T I C L E I N F O}

\section{Article history:}

Received 11 July 2014

Received in revised form

26 September 2014

Accepted 23 October 2014

Available online 30 October 2014

\section{Keywords:}

Lower-risk myelodysplastic syndrome

Outcome

Azacitidine

\begin{abstract}
A B S T R A C T
Scoring systems for lower-risk myelodysplastic syndrome (LR-MDS) recognize patients with a poorer than expected outcome. This study retrospectively analyzes the role of azacitidine in LR-MDS with adverse risk score and compared to an historical cohort treated with best supportive care or erythropoiesisstimulating agents. Overall response to AZA was $40 \%$. One and 2-year probabilities of survival were $62 \%$ and $45 \%$ for AZA vs. $25 \%$ and $11 \%\left(P=10^{-4}\right)$. In a multivariable time-dependent analysis, response to $\mathrm{AZA}(\mathrm{CR} / \mathrm{PR} / \mathrm{HI})$ was associated with an improved survival $(\mathrm{HR}=0.234,95 \% \mathrm{CI}, 0.063-0.0863 ; P=0.029)$. Thrombocytopenia $\left(<50 \times 10^{9} \mathrm{~L}^{-1}\right)$ is confirmed as an adverse parameter in LR-MDS (HR $=1.649,95 \% \mathrm{CI}$, $1.012-2.687 ; P=0.045)$.
\end{abstract}

(c) 2014 Elsevier Ltd. All rights reserved.

\footnotetext{
is This study was presented partly as a poster presentation at the 55th Annual Meeting of the American Society of Hematology, December 7-10, 2013, New Orleans, LA, USA.

* Corresponding author. Tel.: +34 955014 396; fax: +34 955013265

E-mail address: josef.falantes.sspa@juntadeandalucia.es (J. Falantes).

1 On behalf of the Asociación Andaluza de Hematología y Hemoterapia, Spain.

2 On behalf of the Spanish Group of Myelodysplastic Syndromes (GESMD).
}

\section{Introduction}

Myelodysplastic syndromes (MDS) comprise a group of clonal hematopoietic disorders affecting mainly older individuals with median age at diagnosis above 70 years [1]. MDS are characterized by dysplastic features in the bone marrow (BM) evaluation, peripheral blood cytopenia and risk for progression to acute myeloid 
leukemia (AML) [2]. Prognosis of patients with MDS is very heterogeneous. The most commonly used prognostic score for clinical studies in MDS is the International Prognostic Scoring System (IPSS) [3], accounting for the BM blast percentage, number of peripheral cytopenias and karyotype. The IPSS allows identification of lowerrisk (LR-MDS: low and intermediate-1 IPSS scores) from higher-risk (HR-MDS: intermediate-2 and high risk IPSS scores) MDS patients in terms of overall survival (OS) and risk of leukemic progression. Recently, the revised IPSS (IPSS-R) [4] for MDS incorporates a new classification of cytogenetic abnormalities [5], severity of peripheral cytopenias and different cut-off percentages for BM blasts, allowing identification of five, instead of the former four risk categories. In addition, transfusion dependence (TD; defined as having at least one red blood cell transfusion every 8 weeks over a period of 4 months) and degree of anemia were incorporated by the WHO-based Prognosis Scoring System (WPSS) providing risk stratification at any time during the course of the disease [6,7]. However, the concept of LR-MDS, defined as low and intermediate1 risk categories by the IPSS has several limitations. Parameters such as severity of cytopenias, TD and the recent classification of cytogenetic abnormalities are not considered to assess prognosis when using the IPSS [3]. In this setting, two retrospective studies have evaluated the prognostic impact of those variables. GarciaManero et al. [8] reported a prognostic model for lower-risk MDS identifying three risk categories in a large series of LR-MDS patients with significant differences in expected median OS ranging from 80 to 14 months for the group of patients with the most adverse characteristics. A recent study from our institution evaluated 332 LR-MDS patients [9], but only including those with the very good, good and intermediate cytogenetic categories recognized for the IPSS-R [4,5]. In contrast to the MD Anderson prognostic score (MDA score), TD was also included in the survival model, as it has been reported as an independent prognostic factor in MDS [10,11]. This analysis allowed the identification of a subset of LR-MDS with a poorer than expected median OS (13 months), a 10\% estimated 4year survival and an increased risk of progression to AML. Thus, data from these studies may have significant implications when considering treatment approaches for patients with lower-risk disease but displaying adverse prognostic features.

Furthermore, the goal of intervention for MDS patients has been established in the setting of the classic categorization as lower vs. higher-risk MDS. It is currently accepted for that LR-MDS, aim of therapy is focused to improve transfusion needs, improvement of anemia and quality of life [12]. These patients are routinely offered best supportive care (BSC), erythropoiesis-stimulating agents (ESA) or lenalidomide for lower-risk disease with anemia and $5 q$ deletion. Azanucleosides, 5-azacitidine (AZA) and decitabine have also been tried in lower-risk MDS. Several retrospective and prospective studies have shown different rate of hematological improvement and transfusion independency in patients with lower-risk disease by IPSS [13-18]. However, the impact of AZA treatment in the group of LR-MDS with confirmed poor prognosis according to specific lower-risk scores $[8,9]$ is uncertain.

With this background, in the current study we focused on the outcome of patients with lower-risk disease by IPSS [3] who received AZA but displaying adverse clinical features according to an specific risk model for LR-MDS [9] and compared to a historic cohort of patients who only received BSC or ESA as conventional therapies.

\section{Patients and methods}

\subsection{Patients}

For this retrospective analysis, patients categorized as low and intermediate-1 IPSS score [3] included in the Spanish Group of
Table 1

Multivariate analysis for variables with significant impact on outcome in LR-MDS patients. Risk model for survival.

\begin{tabular}{llll}
\hline Variable & HR $(95 \% \mathrm{CI})$ & $P$ & Assigned score \\
\hline Age $>60$ & $1.909(1.256-2.902)$ & 0.002 & 2 \\
$\mathrm{Hb}<10 \mathrm{~g} / \mathrm{dL}$ & $1.701(1.173-2.467)$ & 0.005 & 1 \\
$\mathrm{Plt}<50 \times 10^{9} \mathrm{~L}^{-1}$ & $1.853(1.287-2.667)$ & 0.001 & 2 \\
$\mathrm{BM}$ blast $(4-9 \%)$ & $1.288(1.200-3.045)$ & 0.006 & 1 \\
$\mathrm{TD}$ & $1.548(1.092-2.195)$ & 0.014 & 1 \\
& & & \\
Risk group & & & \\
\hline Score & Median survival (months) & Estimated 4-year survival (\%) \\
\hline $0-2$ & 95 & 72 & \\
$3-4$ & 44 & 40 & \\
$5-7$ & 13 & 10 & \\
\hline
\end{tabular}

Adapted from Falantes et al. [9].

HR indicates hazard ratio; Hb, hemoglobin; Plt, platelet; BM, bone marrow; TD, transfusion dependence.

Myelodysplastic Syndromes (GESMD) registry who were treated with AZA in a compassionate use program in Spain were initially recognized. The score for lower-risk MDS patients proposed by our institution (Hospital Universitario Virgen del Rocío, Seville, Spain) was applied to these patients who received AZA [9]. Patients scoring 5-7 points according to this model as described in Table 1 (age $>60$ years, hemoglobin $<10 \mathrm{~g} / \mathrm{dL}$, transfusion dependence at diagnosis, platelet $<50 \times 10^{9} \mathrm{~L}^{-1}$ and bone marrow blasts percentage $4-9 \%)$ were finally included for analysis $(n=27)$. For comparison, an historical cohort from 2000 to 2010 period who served for the development of the prognostic model for LR-MDS [9] was selected. Patients from this historical cohort who received best supportive care (BSC; $n=46)$ or BSC and ESA $(n=15)$ and only those scoring 5-7 points in the model, were selected.

A total of 88 patients were retrospectively analyzed, those for the AZA-cohort $(n=27)$ and historical control as the non-AZA group $(n=61)$.

All patients in the AZA cohort were aged $\geq 18$ years and provided written informed consent. The study was approved by Local Ethics Committee. Patients from the AZA cohort received at least one course of therapy $\left(75 \mathrm{mg} / \mathrm{m}^{2} /\right.$ day and every 4 weeks). Ten out of 27 patients (37\%) received 5 days schema; eight patients (29.6\%) received 5 days followed by 2 days off and 2 more days and seven patients (26\%) received 7 days schema. No data was available for two patients (7.4\%). Table 2 shows baseline characteristics of the patients and differences between the non-AZA and AZA cohorts.

\subsection{Outcome measures}

The main objective of this retrospective multicenter study was to assess the efficacy of AZA and parameters associated with survival in the group of lower-risk MDS patients with adverse clinical features in the mentioned risk model [9]. Response was evaluated as complete remission (CR), partial remission (PR) or hematological improvement $(\mathrm{HI})$ according to the International Working Group 2006 criteria for MDS [19]. Patients were considered to be responders if response was maintained for 8 weeks or more (Table 3 ).

\subsection{Statistical analysis}

Comparison of continuous variables was performed by the Mann-Whitney $U$ or Student's $t$-test when appropriate. For discrete variables, chi-squared test or Fisher's exact test were performed depending on sample size. Overall survival was calculated from date of diagnosis until death from any cause and estimated by the Kaplan-Meier method [20]. Patients who remained alive were censored at the time of last follow-up. The statistical significance 
Table 2

Baseline characteristics of the patients $(N=81)$ and differences between the non-AZA and AZA cohorts.

\begin{tabular}{|c|c|c|c|c|}
\hline \multirow[t]{2}{*}{ Parameter } & \multicolumn{3}{|l|}{$N(\%)$} & \multirow[t]{2}{*}{$P$ value } \\
\hline & Global & $\begin{array}{l}\text { Non-AZA } \\
(N=61)\end{array}$ & $\begin{array}{l}\text { AZA } \\
(N=27)\end{array}$ & \\
\hline Age (median) & $71(48-86)$ & $70(48-86)$ & $74(62-83)$ & 0.26 \\
\hline $\begin{array}{l}\text { WHO subtype } \\
\text { RA/RARS } \\
\text { RCMD/RS } \\
\text { RAEB-1 } \\
\text { CMML }\end{array}$ & $\begin{array}{l}15(17) \\
34(38.6) \\
19(33) \\
10(11.4)\end{array}$ & $\begin{array}{l}14(22.9) \\
25(41) \\
12(19.7) \\
10(16.4)\end{array}$ & $\begin{array}{l}1(3.7) \\
9(25.9) \\
17(63) \\
0\end{array}$ & $\begin{array}{c}0.02 \\
0.25 \\
<0.001\end{array}$ \\
\hline $\begin{array}{l}\text { LR-MDS score } \\
5 \mathrm{pt} \\
6 \mathrm{pt} \\
7 \mathrm{pt}\end{array}$ & $\begin{array}{l}40(45.4) \\
35(39.8) \\
13(14.8)\end{array}$ & $\begin{array}{l}28(46) \\
27(44) \\
6(10)\end{array}$ & $\begin{array}{l}12(44) \\
8(30) \\
7(26)\end{array}$ & $\begin{array}{l}0.45 \\
0.1 \\
0.03\end{array}$ \\
\hline Transfusion dependence & $73(83)$ & $49(80)$ & $24(96)$ & 0.06 \\
\hline $\begin{array}{l}\text { Karyotype } \\
\text { Normal } \\
\text { del }(5 q) \\
\text { del }(20 q) \\
-Y \\
+8 \\
\text { IM }\end{array}$ & $\begin{array}{l}72(81.9) \\
4(4.5) \\
2(2.3) \\
2(2.3) \\
3(3.4) \\
5(5.6)\end{array}$ & $\begin{array}{l}52(85.3) \\
2(3.3) \\
2(3.3) \\
1(1.6) \\
1(1.6) \\
3(3.9)\end{array}$ & $\begin{array}{l}20(74.1) \\
2(7.4) \\
0 \\
1(3.7) \\
2(7.4) \\
2(7.4)\end{array}$ & $\begin{array}{l}0.23 \\
0.44 \\
0.61 \\
0.24 \\
0.65\end{array}$ \\
\hline $\begin{array}{l}\text { IPSS } \\
0 \\
0.5 \\
1\end{array}$ & $\begin{array}{l}3(3.4) \\
44(50) \\
41(46.6)\end{array}$ & $\begin{array}{l}3(4.8) \\
35(57.1) \\
23(38.1)\end{array}$ & $\begin{array}{l}0 \\
9(30.4) \\
18(69.6)\end{array}$ & $\begin{array}{l}0.03 \\
0.01\end{array}$ \\
\hline $\begin{array}{l}\text { IPSS-R } \\
\text { Very low } \\
\text { Low } \\
\text { Intermediate } \\
\text { High } \\
\text { Very high }\end{array}$ & $\begin{array}{l}0 \\
27 \\
40 \\
21 \\
0\end{array}$ & $\begin{array}{l}0 \\
25(41) \\
29(47.5) \\
7(11.5) \\
0\end{array}$ & $\begin{array}{l}0 \\
2(7.5) \\
11(40.7) \\
14(51.8) \\
0\end{array}$ & $\begin{array}{l}0.001 \\
0.5 \\
<0.001\end{array}$ \\
\hline $\begin{array}{l}\text { Platelet }\left(<50 \times 10^{9} \mathrm{~L}^{-1}\right) \\
\text { ANC }<0.5 \times 10^{9} \mathrm{~L}^{-1} \\
\text { BM blast }(4-9 \%)\end{array}$ & $\begin{array}{l}42(47.7) \\
18(20.4) \\
36(40.8)\end{array}$ & $\begin{array}{l}29(47.5) \\
11(18) \\
18(29.5)\end{array}$ & $\begin{array}{l}13(48) \\
10(39) \\
18(67)\end{array}$ & $\begin{array}{c}0.7 \\
0.06 \\
<0.001\end{array}$ \\
\hline
\end{tabular}

WHO indicates World Health Organization; RA/RARS, refractory anemia/refractory anemia with ringed sideroblasts; RCMD, refractory cytopenia with multilineage dysplasia; RAEB-1, refractory anemia with excess blasts-1; CMML, chronic myelomonocytic leukemia; LR-MDS, lower-risk myelodysplastic syndrome; IM, Insufficient methaphases; IPSS, International Prognostic Scoring System; IPSS-R, Revised International Prognostic Scoring System; ANC, absolute neutrophil count; $\mathrm{BM}$, bone marrow.

of prognostic variables was tested by the log-rank test. To evaluate the relative impact of each parameter on survival, a Cox proportional hazard regression model was performed [21]. As AZA therapy was started at different time-points, multivariable analysis for survival was also performed including AZA treatment as a time-dependent covariate. Also, response to AZA was evaluated as a time-dependent covariate in the multivariable analysis considering responding patients those who achieved CR, PR or HI. Parameters included in the model for survival were: AZA treatment, peripheral cytopenias (anemia and thrombocytopenia considering $<10 \mathrm{~g} / \mathrm{dL}$ and $<50 \times 10 \mathrm{~L}^{-1}$ as thresholds, respectively), percentage of $\mathrm{BM}$ blasts at diagnosis (4-9\%) and TD as previously defined. A landmark analysis was performed to avoid this time-to-treatment bias

Table 3

Multivariate analysis for OS with AZA treatment as time-dependent covariate.

\begin{tabular}{llll}
\hline Parameter & HR & $95 \% \mathrm{CI}$ & $P$ \\
\hline AZA treatment & 1.502 & $0.742-3.039$ & 0.25 \\
Blasts 4-9\% $_{\text {Thrombocytopenia }^{1}}$ & 1.016 & $0.608-1.698$ & 0.95 \\
Neutropenia $^{2}$ & 1.690 & $1.036-2.756$ & 0.03 \\
\hline
\end{tabular}

$1\left(<50 \times 10^{9} \mathrm{~L}^{-1}\right)$

$2\left(<0.5 \times 10^{9} \mathrm{~L}^{-1}\right)$ in the AZA cohort. The time threshold for the Landmark analysis has been chosen so that the most relevant part of the information (response to therapy) is acquired by that time-point. As response was evaluated after 2-4 courses of therapy, a 3-month Landmark analysis was performed. Differences were considered to be statistically significant when two-sided $P$-values were $<0.05$. Statistical analysis was performed with SPSS statistical package (SPSS Inc., Chicago, IL, USA).

\section{Results}

The most common WHO [22] subtype was refractory cytopenia with multilineage dysplasia (RCMD; $n=34 ; 38.6 \%$ ). Patients in the AZA cohort tended to be older (median age 74 vs. $70 ; P=0.26$ ), included more patients with refractory anemia with excess of blasts-1 (RAEB-1; 63\% vs. 20\%; $P<0.001$ ), a higher rate of transfusion dependency ( $96 \%$ vs. $80 \% ; P=0.06$ ), higher IPSS score (IPSS $=1$; $69 \%$ vs. $30 \% ; P=0.01)$, more patients with absolute neutrophil count $\left(\right.$ ANC) $<0.5 \times 10^{9} \mathrm{~L}^{-1}$ (39\% vs. $\left.18 \% ; P=0.06\right)$ and a higher BM blast percentage $(4-9 \%$; $67 \%$ vs. $29.5 \%$; $P<0.001$ ). No significant differences in severe thrombocytopenia was documented between groups, being $<50 \times 10^{9} \mathrm{~L}^{-1}$ in $48 \%$ and $47.5 \%$ of patients in the AZA and non-AZA cohorts, respectively $(P=0.7)$. According to the recent IPSS-R score, only $7 \%$ patients who received AZA were low risk as compared to $41 \%(P=0.001)$ and $51 \%$ were categorized as high risk vs. only $11.5 \%$ in the non-AZA cohort $(P<0.001)$.

Cytogenetic analysis was reported according to the International System for Human Cytogenetic Nomenclature [23] (ISCN) and classified according to IPSS categories [3] and the recent comprehensive cytogenetic scoring system for primary MDS [5]. Overall, $81.9 \%$ of the patients displayed a normal karyotype. No differences were noticed in the distribution of cytogenetic evaluation between the AZA and non-AZA groups. Risk scores in MDS patients were calculated according to IPSS [3], IPSS-R [4] and the lower-risk score proposed by our institution as previously defined [9].

Median time from diagnosis to AZA therapy was 4 months (range: 0.5-21). Median courses of AZA therapy were eight (range: 1-30). At last follow-up, 72 patients ( $81 \%)$ had died $(55 / 61 ; 90 \%$ and $17 / 27 ; 63 \%$ for the non-AZA and AZA groups, respectively).

\subsection{Response to AZA and survival analysis}

The overall response rate $(\mathrm{ORR}=\mathrm{CR} / \mathrm{PR} / \mathrm{HI})$ in the $\mathrm{AZA}$ cohort was $40.7 \%$ (CR: 20\%, PR: $8 \%$, HI: 12\%). Response was evaluated between second and fourth courses of therapy in all cases. After a median follow-up of 17 months, the projected actuarial oS for the overall series was $40 \%$ and median OS was 18 months. By conventional Kaplan-Meier plots, the actuarial probabilities of OS at 1 and 2 years were: $62.4 \%$ and $45 \%$ for AZA-treated patients and $25.4 \%$ and $11 \%$ for non-AZA treated patients $(P=0.001)$. In a multivariable analysis including BM blast \% ( $<4 \%$ vs. $4-9 \%$ ), neutropenia ( $<0.5$ vs. $\left.>0.5 \times 10^{9} \mathrm{~L}^{-1}\right)$, thrombocytopenia ( $<50$ vs. $\left.>50 \times 10^{9} \mathrm{~L}^{-1}\right)$ and AZA treatment as time-dependent covariate, the later did not showed statistical significance (hazard ratio $[\mathrm{HR}]=1.502$, 95\% confidence interval $[\mathrm{CI}], 0.258-3 ; P=0.258)$. Only severe thrombocytopenia $\left(<50 \times 10^{9} \mathrm{~L}^{-1}\right)$ appeared to be significant in multivariable timedependent analysis with a negative impact on OS ( $\mathrm{HR}=1.690,95 \%$ CI, 1.036-2.756; $P=0.03$, Table 4 ). In a multivariable analysis including response to AZA therapy also as time-dependent covariate (CR, PR or HI); patients who achieved any type of response had a significantly reduced risk of death when compared to those not achieving response to AZA and those treated with $\mathrm{BSC}$ and/or $\mathrm{ESA}(\mathrm{HR}=0.234$; 95\% CI, 0.063-0.863; $P=0.029$, Table 4). As response was evaluated after 2-4 courses of therapy, a 3-month landmark analysis was performed. This analysis showed a survival advantage for patients 


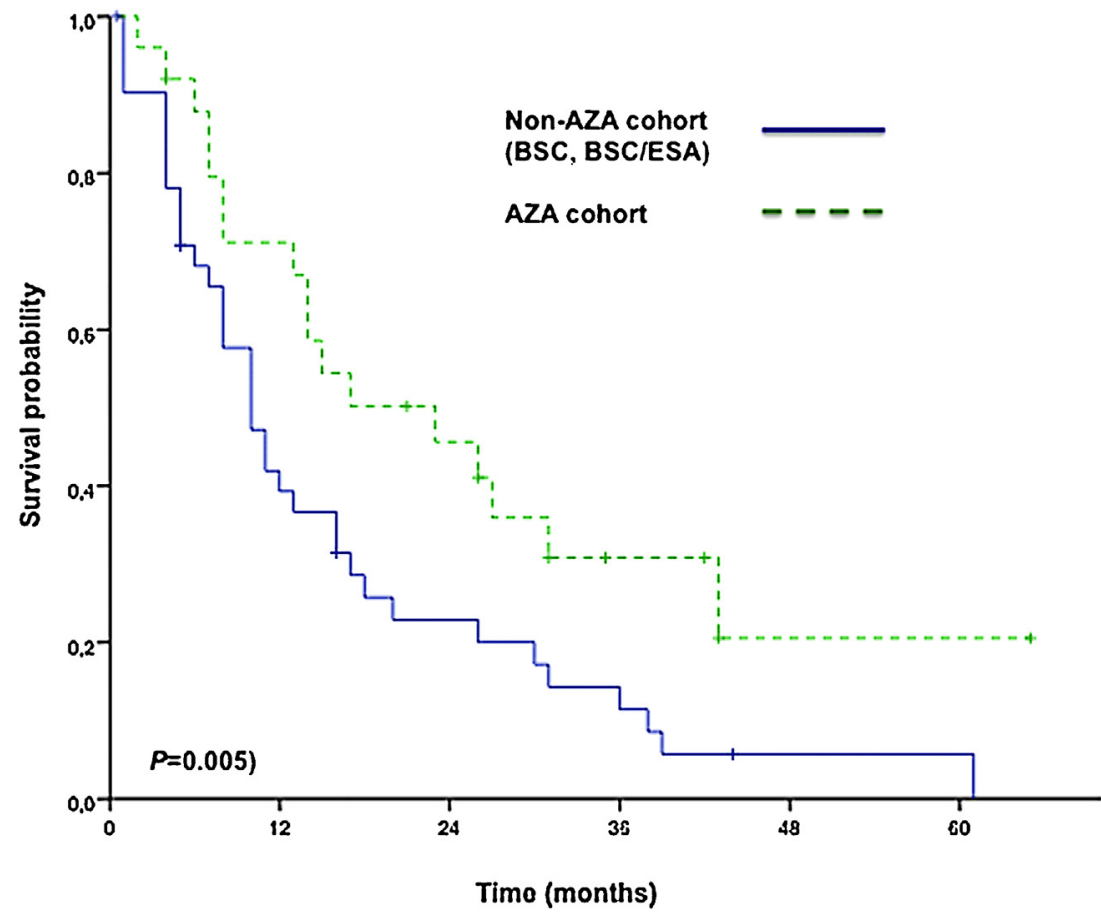

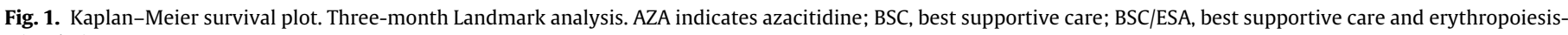
stimulating agents.

treated with AZA as compared to non-AZA cohort (median OS: 10 months [non-AZA] vs. 23 months [AZA]; $P=0.005$ ). The estimated OS rate at 12 and 24 months was: $31.5 \%$ and $5.7 \%$ for the non-AZA group and $62.4 \%$ and $45.1 \%$ for the AZA group, respectively (Fig. 1). Progression to acute myeloid leukemia (AML) occurred in $24.6 \%$ of patients who did not receive AZA and $14.8 \%$ for AZA-treated patients $(P=0.19)$. Hematological toxicity related to AZA was not assessed as the majority of patients had significant clinically anemia (96\%), neutropenia with ANC $<0.5 \times 10^{9} \mathrm{~L}^{-1}$ (39\%) and thrombocytopenia $<50 \times 10^{9} \mathrm{~L}^{-1}(48 \%)$ at the time of initiation of AZA. As for data available, skin reaction after subcutaneous administration was the most common toxicity (all of them grade $<2$ ). No death-related to AZA was reported.

\section{Discussion}

Azacitidine (Vidaza ${ }^{\circledR}$; Celgene Corporation, Summit, NJ, USA) was approved on 2004 by the U.S. Food and Drug Administration [24] for patients with all subtypes of MDS based on response rate, reduction of transfusion dependence, decreased risk of progression to AML, improvement of quality of life and increase in overall survival compared with supportive care; whereas in Europe is only licensed for intermediate-2/high risk IPSS patients ineligible

Table 4

Multivariate analysis for OS with response as a time-varying covariate.

\begin{tabular}{llll}
\hline Parameter & HR & $95 \% \mathrm{CI}$ & $P$ \\
\hline AZA treatment & 1.606 & $0.754-3.420$ & 0.22 \\
Blasts 4-9\% $_{\text {Thrombocytopenia }^{1}}$ & 0.828 & $0.487-1.409$ & 0.48 \\
Neutropenia $^{2}$ & 1.649 & $1.012-2.687$ & 0.045 \\
Overall response (CR/PR/HI) & 0.674 & $0.363-1.253$ & 0.21 \\
\hline
\end{tabular}

CR indicates complete remission; PR, partial remission; HI, hematological improvement.

$1\left(<50 \times 10^{9} \mathrm{~L}^{-1}\right)$

$2\left(<0.5 \times 10^{9} \mathrm{~L}^{-1}\right)$ for hematopoietic stem cell transplantation. In these IPSS categories, as well as in low-blast percentage AML by WHO criteria [25] (RAEB in transformation according to the French-British-American classification), AZA has resulted in an improved survival when compared to conventional care regimens in a randomized phase III trial [26]. AZA has also been tried in lower-risk MDS subtypes according to the IPSS [3] and its use in this group of patients has been evaluated in several prospective and retrospective studies. Most of theses studies were not specifically designed to evaluate AZA in a group of lower-risk disease and data came from additional analysis. A subanalysis from a randomized study of the cancer and leukemia group B (CALGB) evaluating patients with LR-MDS treated with AZA (7 days schedule) showed an ORR of $59 \%$ and survival advantage as compared to patients who received supportive care $[13,14]$. Also, different schedules of AZA dosing have been prospectively evaluated, particularly in a group of lower-risk disease, with primary endpoint of clinical response and transfusion independence, achieved in up to $60 \%$ of patients [15]. A recent prospective, multicenter, phase II study in low and intermediate-1 IPSS MDS patients showed an ORR of 47\% [16]. However, population of patients from this analysis with LR-MDS significantly differs from the group of patients herein reported in our analysis. Most of those patients had an IPSS score $<0.5$ (72\%), and only $12 \%$ were platelet transfusion dependent; meaning that only a small fraction of them would meet criteria previously reported as having adverse LR-MDS features. In addition, median time from diagnosis to therapy with AZA was 20 months, significantly longer than the expected median OS for the population of patients reported in the two prognostic models for LR-MDS with poor risk features (13-14 months) [8,9]. Also, no patient from this study progressed to AML as compared with the same percentage (14\%) reported in both prognostic models for LR-MDS [8,9]. The Nordic MDS Group sponsored a phase II trial in low and intermediate-1 IPSS MDS patients refractory or with low probability of response to erythropoiesis-stimulating agents (ESA) [17]. Thirty patients dependent on red blood cell transfusion were enrolled. Severe thrombocytopenia $\left(<30 \times 10 \mathrm{~L}^{-1}\right)$ or elevated blast 
count was present in only three and four patients, respectively. Primary end point was defined as transfusion independence and erythroid response was 30\%, lower than reported in prior reports attributed to the selection of resistant patients to ESA. None of the previous studies have assessed the role of AZA, and moreover, its possible impact on survival on lower-risk MDS patients with specific adverse risk score [8,9]. Only a retrospective study conducted in Italy in patients with lower-risk MDS [18] analyzed clinical responses focusing in the subgroup that displayed adverse risk score according to the M.D. Anderson model [8]. Only 18 patients had adverse specific adverse score for lower-risk patients, with a reported ORR of 33.3\% and projected OS after 15 months median follow-up of $48.7 \%$.

In this multicenter retrospective study conducted in Spain, a total of 27 patients with lower-risk MDS and adverse clinical features according to a recently published risk score for lower-risk disease (category 3, score $>5$; expected median OS: 13 months, and estimated 4 -year survival: $10 \%$ ) received AZA in a compassionate program and were compared to a historic cohort of patients ( $n=61$ ) that served as the basis for the development of the prognostic score for lower-risk MDS [9]. Most of patients who received AZA were older than 70 years, were transfusion dependent on red blood cells (96\%), almost a third of them had BM blast ranging from 4 to $9 \%$ and half of them had severe thrombocytopenia; parameters all considered to be related to an adverse outcome $[8,9]$. In addition, over a half of them would be considered as high risk category by IPSS-R although none of these patients, as well as patients in the non-AZA cohort, had cytogenetic categories other than good/intermediate by the IPSS [3] or very good/good/intermediate by the recent classification of cytogenetics used for the IPSS-R [4].

AZA showed an ORR in up to $40 \%$ of these patients with classic lower-risk disease by IPSS but with unfavorable parameters with significant impact on survival $[8,9]$. Moreover, $40 \%$ of patients in the AZA cohort were alive after a median follow-up of 17 months. These median follow-up was significantly longer than the expected median OS for the comparison cohort in which only BSC and/or ESA were offered (13 months median OS for patients with score for LR-MDS ranging 5-7 points) [9].

These data, although retrospective and limited number of patients included, with the potential bias inherent in this type of analysis, should reconsider the current recommendation that active therapies (other than BSC, ESA) must not be offered to lower-risk MDS patients until disease progression, or alternatively, been considered as high-risk MDS patients. In fact, a study conducted in 274 LR-MDS patients showed that as high as $85 \%$ of all deaths in this patient population were related to the underlying disease rather than other unrelated causes [27]. Therefore, identification of patients with poor prognosis according to the risk models for LR-MDS could be considered, or candidates, in the context of clinical trials if possible, for early intervention. Also, design of trials and evaluation of novel therapies for lowerrisk MDS, should consider this patients separately from the rest of lower-risk disease. In this setting, a novel oral formulation of AZA is currently being tested in patients with lower-risk MDS with transfusion dependency and severe thrombocytopenia in an international multicenter phase III randomized trial (NCT01566695).

In summary, very limited data regarding the efficacy of AZA in lower-risk MDS patients within the most adverse specific lowerrisk model are available to date. In this subset of patients and using multivariable time-dependent analysis, AZA appeared to increase survival in those who achieved some degree of hematological response (CR, PR or $\mathrm{HI})$. Larger number of patients and prospective randomized trials considering early intervention are needed to better address this issue. Thrombocytopenia $\left(<50 \times 10^{9} \mathrm{~L}^{-1}\right)$ was confirmed as the most significant clinical parameter with impact on outcome in lower-risk MDS categories.

\section{Conflict of interest statement}

All authors have no conflict of interest to report.

\section{Acknowledgements}

Contributions: J. F. F, J. A. P-S and G. S. provided the conception and design of the study, supplied the acquisition of data, analysis and interpretation of data, revised the article critically for important intellectual content and gave final approval of the version submitted. R. G-D, C. C, F. J. M-M, D. V, D. M, A. B, J. B, T. B, J.R. G-P, M. T, F. R, A. L, B. X, B. N, S. B, J. S, A. F-J, S. B and supplied the acquisition of data and revised it critically for important intellectual content.

\section{References}

[1] Rollison DE, Howlader N, Smith MT, et al. Epidemiology of myelodysplastic syndromes and chronic myeloproliferative disorders in the United States, 2001-2004, using data from the NAACCR and SEER programs. Blood 2008; $112: 45-52$

[2] Tefferi A, Vardiman JW. Myelodysplastic syndromes. N Engl J Med 2009;361(November (19)):1872-85.

[3] Greenberg P, Cox C, LeBeau MM, et al. International scoring system for evaluating prognosis in myelodysplastic syndromes. Blood 1997;89:2079-88.

[4] Greenberg PL, Tuechler H, Schanz J, et al. Revised international prognostic scoring system for myelodysplastic syndromes. Blood 2012;120(September (12)):2454-65

[5] Schanz J, Tüchler H, Solé F, et al. New comprehensive cytogenetic scoring system for primary myelodysplastic syndromes (MDS) and oligoblastic acute myeloid leukemia after MDS derived from an international database merge. J Clin Oncol 2012;30(March (8)):820-9.

[6] Malcovati L, Germing U, Kuendgen A, et al. Time-dependent prognostic scoring system for predicting survival and leukemic evolution in myelodysplastic syndromes. J Clin Oncol 2007;25(August (23)):3503-10.

[7] Malcovati L, Della Porta MG, Strupp C, et al. Impact of the degree of anemia on the outcome of patients with myelodysplastic syndrome and its integration into the WHO classification-based Prognostic Scoring System (WPSS). Haematologica 2011;96(October (10)):1433-40.

[8] Garcia-Manero G, Shan J, Faderl S, et al. A prognostic score for patients with lower risk myelodysplastic syndrome. Leukemia 2008;22:538-43.

[9] Falantes J, Calderón C, Márquez-Malaver FJ, et al. Clinical prognostic factors for survival and risk of progression to acute myeloid leukemia in patients with myelodysplastic syndromes with less than $10 \%$ bone marrow blasts and non unfavorable cytogenetic categories. Clin Lymphoma Myeloma Leuk 2013;13(April (2)):144-52.

[10] Malcovati L, Porta MG, Pascutto C, et al. Prognostic factors and life expectancy in myelodysplastic syndromes classified according to WHO criteria: a basis for clinical decision making. J Clin Oncol 2005;23(October (30)):7594-603.

[11] Sanz G, Nomdedeu B, Such E, et al. Independent impact of iron overload and transfusion dependency on survival and leukemic evolution in patients with myelodysplastic syndrome. ASH Annu Meet Abstr 2008 [Abstract 640].

[12] Garcia-Manero G. Myelodysplastic syndromes: 2014 update on diagnosis, riskstratification, and management. Am J Hematol 2014;89(January (1)):97-108.

[13] Silverman LR, Demakos EP, Peterson BL, et al. Randomized controlled trial of azacitidine in patients with the myelodysplastic syndrome: a study of the cancer and leukemia group B. J Clin Oncol 2002;20(May (10)):2429-40.

[14] Silverman LR, McKenzie DR, Peterson BL, et al. Further analysis of trials with azacitidine in patients with myelodysplastic syndrome: studies 8421,8921 , and 9221 by the cancer and leukemia group B. J Clin Oncol 2006;24:3895-903.

[15] Lyons RM, Cosgriff TM, Modi SS, et al. Hematologic response to three alternative dosing schedules of azacitidine in patients with myelodysplastic syndromes. J Clin Oncol 2009;27:1850-6.

[16] Fili C, Malagola M, Follo MY, et al. Prospective phase II study on 5-days azacitidine (5d-AZA) for treatment of symptomatic and/or erythropoietin unresponsive patients with low/int-1 risk myelodysplastic patients. Clin Cancer Res 2013;19:3308-927308.

[17] Tobiasson M, Dybedahl I, Holm MS, et al. Limited clinical efficacy of azacitidine in transfusion-dependent, growth factor-resistant, low-and Int-1 risk MDS: results from the nordic NMDSG08A phase II trial. Blood Cancer J 2014;4(March):e189, http://dx.doi.org/10.1038/bcj.2014.8.

[18] Musto P, Maurillo L, Spagnoli A, et al. Azacitidine for the treatment of lower risk myelodysplastic syndromes: a retrospective study of 74 patients enrolled in an Italian named patient program. Cancer 2010;116:1485-94. 
[19] Cheson BD, Greenberg PL, Bennett JM, et al. Clinical application and proposal for modification of the International Working Group (IWG) response criteria in myelodysplasia. Blood 2006;108:419-25.

[20] Kaplan EL, Meier P. Nonparametric estimation for incomplete observations. J Am Stat Assoc 1958;53:457-81.

[21] Cox DR. Regression models and life-tables. J R Stat Soc Ser B 1972;34:184-92.

[22] Harris NL, Jaffe E, Diebold J, et al. The World Health Organization classification of neoplastic diseases of the hematopoietic and lymphoid tissues: report of the Clinical Advisory Committee meeting. J Clin Oncol 1999;17:3835-49.

[23] An international system for Human Cytogenetic Nomenclature (2009).Shaffer LG, Slovak ML, Campbell LJ, editors. Recommendations of the International Standing Committee on Human Cytogenetic Nomenclature. Basel, Switzerland: Karger; 2009.
[24] Kaminskas E, Farrell AT, Wang YC, et al. FDA drug approval summary: azacitidine (5-azacytidine, Vidaza) for injectable suspension. Oncologist 2005;10(March (3)):176-82.

[25] Vardiman JW, Thiele J, Arber DA, et al. The 2008 revision of the World Health Organization (WHO) classification of myeloid neoplasms and acute leukemia: rationale and important changes. Blood 2009;114: 937-51.

[26] Fenaux P, Mufti GJ, Hellstrom-Lindberg E, et al. Efficacy of azacitidine compared with that of conventional care regimens in the treatment of higher-risk myelodysplastic syndromes: a randomized, open-label, phase III study. Lancet Oncol 2009;10(March (3)):223-32.

[27] Dayyani F, Conley AP, Strom SS, et al. Cause of death in patients with lower-risk myelodysplastic syndrome. Cancer 2010;116(May (9)):2174-9. 